Article

\title{
Enhanced Photocatalytic Degradation of Caffeine Using Titanium Dioxide Photocatalyst Immobilized on Circular Glass Sheets under Ultraviolet C Irradiation
}

\author{
Rattana Muangmora ${ }^{1}\left(\mathbb{D}\right.$, Patiya Kemacheevakul ${ }^{1,2,3, * \mathbb{D}}$, Patiparn Punyapalakul ${ }^{4,5}$ and \\ Surawut Chuangchote 3,6 (D) \\ 1 Department of Environmental Engineering, Faculty of Engineering, King Mongkut 2019s University of \\ Technology Thonburi, 126 Prachauthit Rd., Bangmod, Bangkok 10140, Thailand; yayarattana@gmail.com \\ 2 Center of Excellence on Hazardous Substance Management (HSM), Bangkok 10330, Thailand \\ 3 Research Center of Advanced Materials for Energy and Environmental Technology (MEET), King Mongkut's \\ University of Technology Thonburi, 126 Prachauthit Rd., Bangmod, Bangkok 10140, Thailand; \\ surawut.chu@kmutt.ac.th \\ 4 Department of Environmental Engineering, Faculty of Engineering, Chulalongkorn University, \\ Bangkok 10330, Thailand; patiparn.p@chula.ac.th \\ 5 Research Unit of Control of Emerging Micropollutants in Environment, Chulalongkorn University, \\ Bangkok 10330, Thailand \\ 6 Department of Tool and Materials Engineering, Faculty of Engineering, King Mongkut's University of \\ Technology Thonburi, 126 Prachauthit Rd., Bangmod, Bangkok 10140, Thailand \\ * Correspondence: patiya.kem@kmutt.ac.th; Tel.: +66-2-470-9360; Fax: +66-2-470-9165
}

Received: 24 July 2020; Accepted: 13 August 2020; Published: 22 August 2020

check for updates

\begin{abstract}
This work presents the development of titanium dioxide $\left(\mathrm{TiO}_{2}\right)$ film immobilized on circular glass sheets for photocatalytic degradation of caffeine under ultraviolet C (UVC) irradiation. $\mathrm{TiO}_{2}$ was synthesized through the ultrasonic-assisted sol-gel method and immobilized on circular glass sheets by the doctor blade technique. Polyvinylpyrrolidone (PVP) was used to mix with the $\mathrm{TiO}_{2}$ precursor solution to enhance film adhesion on the glass surface. $\mathrm{TiO}_{2}$ film was mainly composed of anatase phase with a small amount of rutile phase. Caffeine removal was found to increase with increasing irradiation time. Caffeine $(20 \mathrm{mg} / \mathrm{L})$ in the synthetic wastewater could not be detected after $3 \mathrm{~h}$ of UVC irradiation. The reaction rate of caffeine degradation followed the pseudo-first-order model. The concentrated caffeine solutions required a longer irradiation time for degradation. The used $\mathrm{TiO}_{2}$-coated glass sheets could be easily separated from the treated wastewater and reusable. The caffeine removal efficiency of $\mathrm{TiO}_{2}$-coated glass sheets in each cycle maintained a high level ( 100\%) during fifteen consecutive cycles.
\end{abstract}

Keywords: titanium dioxide; photocatalytic degradation; caffeine; ultraviolet C; photocatalysis

\section{Introduction}

Micro-organic pollutants are emerging substances mostly derived from human activities, such as pharmaceuticals and personal care products (PPCPs), perfluorooctane sulfonate (PFOS), perfluorooctanoic acid (PFOA), pesticides, herbicides and many other compounds used in households, hospitals, industries, as well as agricultural areas. Although these substances have been detected in the natural water bodies with a trace concentration, it could be high enough to pose threats to the aquatic living organisms and affect the ecological balance [1,2]. 
Caffeine $\left(\mathrm{C}_{8} \mathrm{H}_{10} \mathrm{~N}_{4} \mathrm{O}_{2}\right)$ is one of the most important substances in a group of pharmaceuticals and personal care products. It is a psychoactive chemical substance with a bitter taste, which can typically be found in beverages (e.g., coffee, tea, soft drinks, and energy drinks), food products (e.g., chocolate, ice cream, candy), and some medicines [3-5]. In the case of medicines, caffeine is used as a common component of the central nervous system stimulants, bronchial and cardiac stimulants, weight control products, pain relievers, diuretics, as well as the drugs for acne and skin disorder treatments [6]. Caffeine persists in water with a relatively long half-life time of 10 years [7]. Moreover, it has high water solubility $\left(\mathrm{K}_{\mathrm{s}}>10,000 \mathrm{mg} / \mathrm{L}\right)$ [8], a very low octanol-water partition coefficient $\left(\log \mathrm{K}_{\mathrm{ow}}=-0.07\right)$, and insignificant volatility. More than $80 \%$ of working people in developed countries consume caffeine everyday [3]. The average consumption rate of caffeine based on the global population is approximately 80 to $400 \mathrm{mg} /$ person/day [7]. The remaining amounts of coffee and caffeinated soft drinks from consumption are the main sources of caffeine contaminated into the wastewater treatment plants [9].

Nowadays, the conventional treatment process in municipal wastewater treatment plants cannot completely degrade caffeine from wastewater $[10,11]$. As a result, the caffeine remaining in the treated wastewater will be discharged into natural water bodies such as surface water and groundwater at a trace concentration from $\mathrm{ng} / \mathrm{L}$ to $\mu \mathrm{g} / \mathrm{L}[12,13]$. The toxicological effects of caffeine do not seem to be a threat to the aquatic living organisms for short time exposure [14]. On the other hand, the long-term continuous release of caffeine into the aquatic environment can lead to sublethal effects on the aquatic living organisms such as oxidative stress and lipid peroxidation in Diopatra neapolitana and Arenicola marina [15,16]. Furthermore, the coral bleaching and the inhibitory effects on algae growth could be presented when the contamination level of caffeine is more than $30 \mathrm{mg} / \mathrm{L} \mathrm{[13]}$. Several methods have been investigated for degradation of caffeine in aqueous solutions such as ozonation [17,18], photo-Fenton [19,20], chlorination [21], UV photolysis [22], and semiconductor-based photocatalysis $[4,8,11,13]$. Ozonation performs the slow reaction rates in caffeine removal. Moreover, many reaction intermediates and transformation products are found during the degradation of caffeine by ozonation [3]. The reaction between caffeine and ferrate (VI) in photo-Fenton is also slow [5]. Chlorination exhibits slow reaction rates between aqueous hypochlorous acid and caffeine [5]. UV photolysis is not effective for the removal of caffeine [22].

Semiconductor photocatalysis is a promising method to remove the dissolved organic compounds in water (e.g., organic dyes, drugs, and pesticides) by the illumination of light at suitable photon energy over the semiconductor photocatalysts $[23,24]$. One of the main reasons is that it performs a high ability in degradation and mineralization of organic pollutants in water under the ambient temperature and pressure. The semiconductors that have been applied as photocatalysts are $\mathrm{TiO}_{2}$, $\mathrm{ZnO}, \mathrm{Fe}_{2} \mathrm{O}_{3}, \mathrm{WO}_{3}, \mathrm{SnO}_{2}$, and $\mathrm{ZrO}_{2}$ [25-28]. $\mathrm{TiO}_{2}$ has been considered as an effective photocatalyst because of its easy availability, cheapness, nontoxicity, long-term physicochemical stability, and solar energy harvesting $[23,29]$. Based on the recently published research, there are a number of works focused on the degradation of caffeine by $\mathrm{TiO}_{2}$-based photocatalysis. Different forms of $\mathrm{TiO}_{2}$ were used as photocatalysts, including commercial $\mathrm{TiO}_{2}$ powder suspended in caffeine solution [5,13], $\mathrm{TiO}_{2}$ nanotubular film immobilized on titanium foil [11], and commercial $\mathrm{TiO}_{2}$ powder (Degussa P25) immobilized on microscopy glass substrates [11]. The suspension of commercial $\mathrm{TiO}_{2}$ powder showed high activity in photocatalytic degradation of caffeine $[5,13]$. Unfortunately, those processes are inappropriate to apply to large-scale processes because of the difficulty in the separation of $\mathrm{TiO}_{2}$ powder from the treated wastewater [29].

Immobilization of $\mathrm{TiO}_{2}$ on solid materials is an alternative solution to overcome the limitation of $\mathrm{TiO}_{2}$ powder suspension. Arfanis et al. [11] reported that P25 powder immobilized on glass substrates showed more activity than $\mathrm{TiO}_{2}$ nanotubular film immobilized on titanium foil under the same operating conditions. However, the significant drawback of P25 film was also observed, i.e., P25 powders were detached from glass substrates during the experiment. Therefore, it is necessary to develop a $\mathrm{TiO}_{2}$ film with good adherence to the glass substrate. One of the practical strategies to 
improve the adhesion properties of $\mathrm{TiO}_{2}$ film on supporting materials is the use of polymers as the binders $[30,31]$. Polyvinylpyrrolidone (PVP) is a thermoplastic polymer with nontoxic and hydrophilic properties [32]. PVP and its derivatives have been extensively applied in the industries of medicine, personal care products, beverages, cosmetics, paints, etc. [33]. There are several previously available reports about applications of PVP and its derivatives. For example, they were used as supports for metal catalytic systems [34,35], drug delivery [32], bone tissue generation [36], energy storage [37], and others. Furthermore, it has been reported that PVP can be used as a polymer binder to enhance the film-forming for $\mathrm{TiO}_{2}$ coating. $\mathrm{TiO}_{2}$ films with the assistance of PVP gave satisfactory results for photocatalytic oxidations of organic pollutants, such as Amido black-10B [30], methylene blue [31,38], and methyl orange [39]. However, the use of immobilized $\mathrm{TiO}_{2}$ film as a photocatalyst in the degradation of caffeine remains scarce.

This work focuses on the development of $\mathrm{TiO}_{2}$ film with good adherence to the surface of circular glass sheets for the degradation of caffeine. $\mathrm{TiO}_{2}$ was synthesized via the ultrasonic-assisted sol-gel method and immobilized on circular glass sheets by the doctor blade technique. Polyvinylpyrrolidone was added to the $\mathrm{TiO}_{2}$ sol in order to induce the polymeric film-forming and enhance the film adhesion on the glass surface. The prepared $\mathrm{TiO}_{2}$ immobilized on circular glass sheets were used in the photocatalytic degradation of caffeine. The effects of irradiation time, initial caffeine concentration, and photocatalyst reusability were investigated.

\section{Results}

\subsection{Characterizations of $\mathrm{TiO}_{2}$ Film Immobilized on Glass Sheets}

\subsubsection{Morphology of $\mathrm{TiO}_{2}$ Film}

Scanning electron microscopy (SEM) images of $\mathrm{TiO}_{2}$ film immobilized on glass sheets are illustrated in Figure 1. There are no cracks in the $\mathrm{TiO}_{2}$ film because polyvinylpyrrolidone in the $\mathrm{TiO}_{2}$ gel solution can inhibit the violent evaporation of the solvent after coating on the solid substrates [31]. As can be seen in the cross-sectional image (Figure 1C), the $\mathrm{TiO}_{2}$ particles relatively flatten on the glass surface. The average $\mathrm{TiO}_{2}$ film thickness is $1.61 \pm 0.24 \mu \mathrm{m}$. $\mathrm{TiO}_{2}$ films coated on substrates were composed of squeezed sphere-like $\mathrm{TiO}_{2}$ particles because they were firmly pressed by a stirring rod during the doctor blade coating technique [31]. It was found that the glass surface is covered by $\mathrm{TiO}_{2} \mathrm{particles}$ with nearly orbicular shape from the top view (Figure 1D).

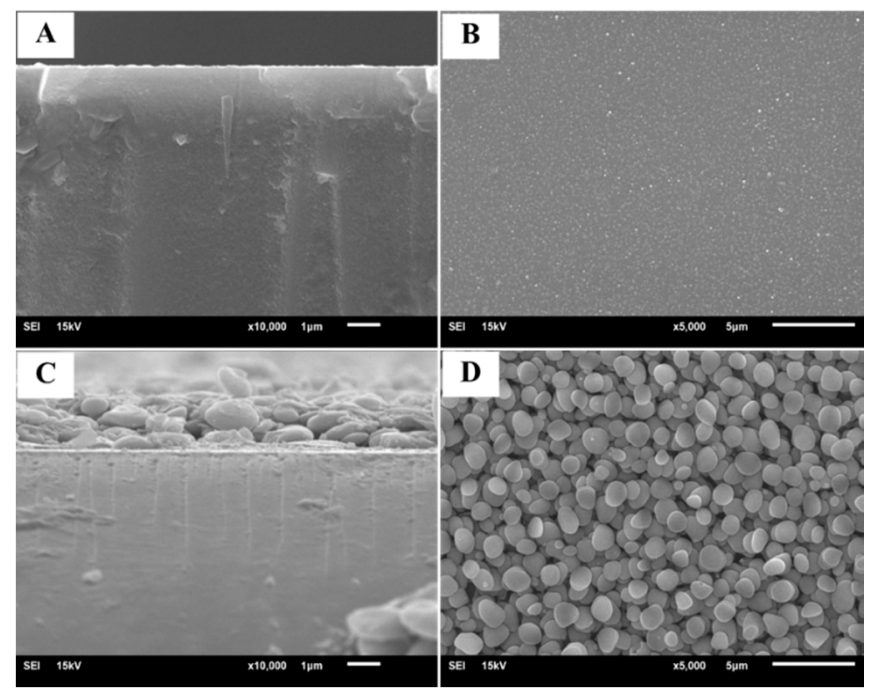

Figure 1. Scanning electron microscopy (SEM) images: (A) cross sectional image of uncoated glass $(10,000 \times),(B)$ surface image of uncoated glass $(5000 \times),(C)$ cross sectional image of $\mathrm{TiO}_{2}$-coated glass $(10,000 \times)$, and $(\mathbf{D})$ surface image of $\mathrm{TiO}_{2}$-coated glass $(5000 \times)$. 


\subsubsection{Crystalline Structure of $\mathrm{TiO}_{2}$ Film}

The result of the X-ray diffraction (XRD) analysis of $\mathrm{TiO}_{2}$ film immobilized on a glass sheet is shown in Figure 2. It can be seen that the diffraction peaks are corresponding to anatase $\mathrm{TiO}_{2}$. The characteristic peak of anatase at the diffraction angle of $25.4^{\circ}$ was detected with the highest intensity. Apart from the anatase phase, a diffraction peak corresponding to the rutile phase was also detected with relatively less intensity. Therefore, the synthesized $\mathrm{TiO}_{2}$ film in this study was mainly composed of the anatase phase with a small track of the rutile phase. Ohno et al. [40] proposed that the mixture of phase anatase and rutile phase is the most suitable form of $\mathrm{TiO}_{2}$ photocatalysts. The synergistic effects of anatase and rutile phase could lead to higher photocatalytic performance in the degradation of organic pollutants in water, compared with isolated anatase or rutile phase. The crystallite size obtained using Scherrer's formula was $11.13 \mathrm{~nm}$. Sirirerkratana et al. [31] reported the sol-gel synthesis of $\mathrm{TiO}_{2}$ without applying ultrasonic wave. It was observed that the crystallite size of $\mathrm{TiO}_{2}$ in this work (with the ultrasonic wave) was smaller than that reported by Sirirerkratana et al. [31]. Neppolian et al. [41] also reported that the $\mathrm{TiO}_{2}$ prepared by ultrasonic-assisted sol-gel method could possess a smaller crystallite size than the sol-gel method. The reason was that ultrasonic waves could produce cavitation bubbles in the $\mathrm{TiO}_{2}$ solution, resulting in the formation of small crystallite sizes of $\mathrm{TiO}_{2}$ [42].

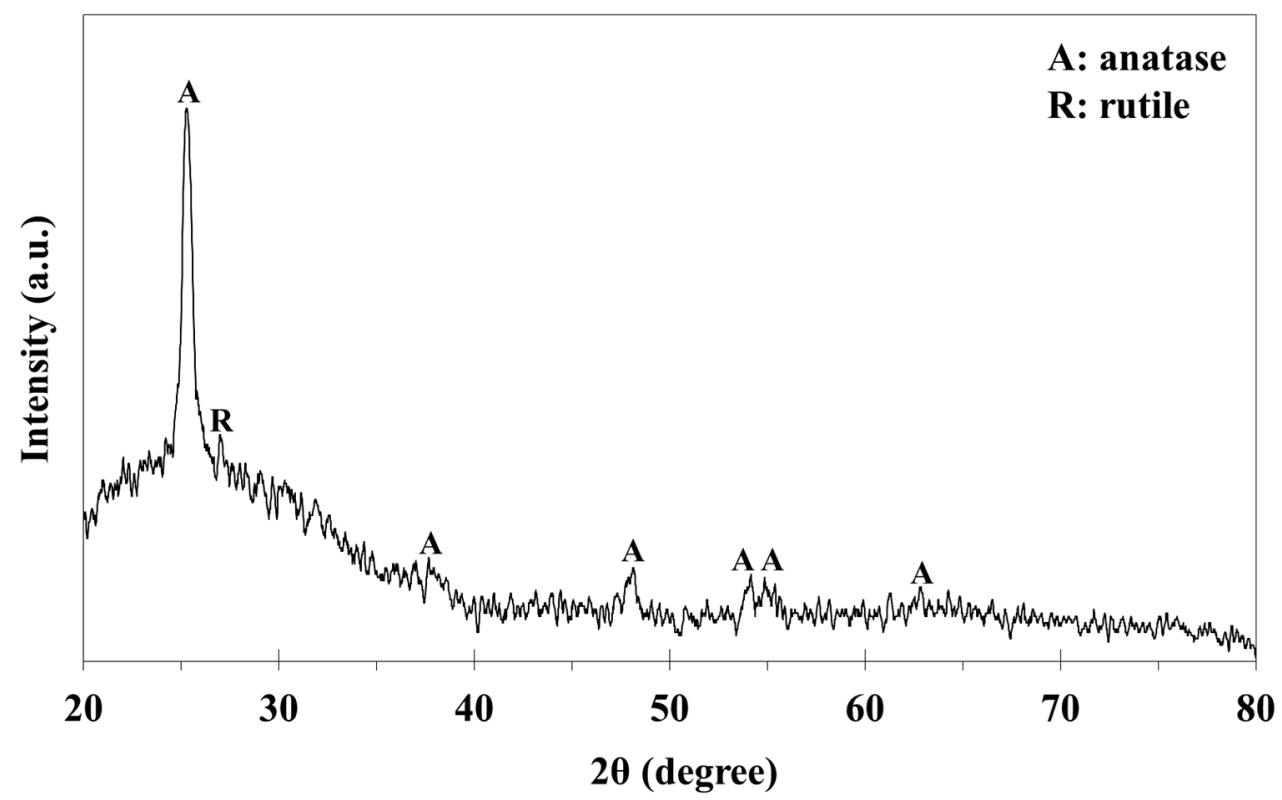

Figure 2. X-ray diffraction (XRD) pattern of $\mathrm{TiO}_{2}$ film immobilized on glass sheet.

\subsection{Degradation of Caffeine by Photocatalytic Process}

\subsubsection{Effects of Irradiation Time and Photocatalyst Coated}

The effects of irradiation time have been investigated with an initial caffeine concentration of $20 \mathrm{mg} / \mathrm{L}$. Figure 3 shows the efficiencies of caffeine removal under ultraviolet C (UVC) irradiation over the uncoated and $\mathrm{TiO}_{2}$-coated glass sheets. For the uncoated glass sheet, the caffeine concentration was insignificantly reduced. The concentration maintained as high as the initial concentration after $3 \mathrm{~h}$ of UVC irradiation. This result is in agreement with the literature reported by Shu et al. [22], which studied the treatment of caffeine in water by direct photolysis at the wavelength range of 200-300 nm (UVC and UVB). It was found that direct photolysis is not having the ability to degrade caffeine in water because the reaction rate constant is very low. $\mathrm{For} \mathrm{TiO}_{2}$-coated glass sheets, the adsorption of caffeine molecules on the surface of $\mathrm{TiO}_{2}$ film reached equilibrium within $1 \mathrm{~h}$ in the dark condition. After that, the UVC irradiation was performed. Caffeine was not completely detected after $3 \mathrm{~h}$ of irradiation. The efficiencies of caffeine removal were $69.52 \%, 90.11 \%$, and $99.75 \%$ at 60,120 , and $180 \mathrm{~min}$ of UVC 
irradiation, respectively. This result indicated that the efficiency of caffeine removal could be enhanced by increasing irradiation time in the case of the photocatalyst-coated sample. Arfanis et al. [11] also reported that the efficiencies of caffeine removal at the natural $\mathrm{pH}$ increased by increasing UV irradiation time in the photocatalytic process.

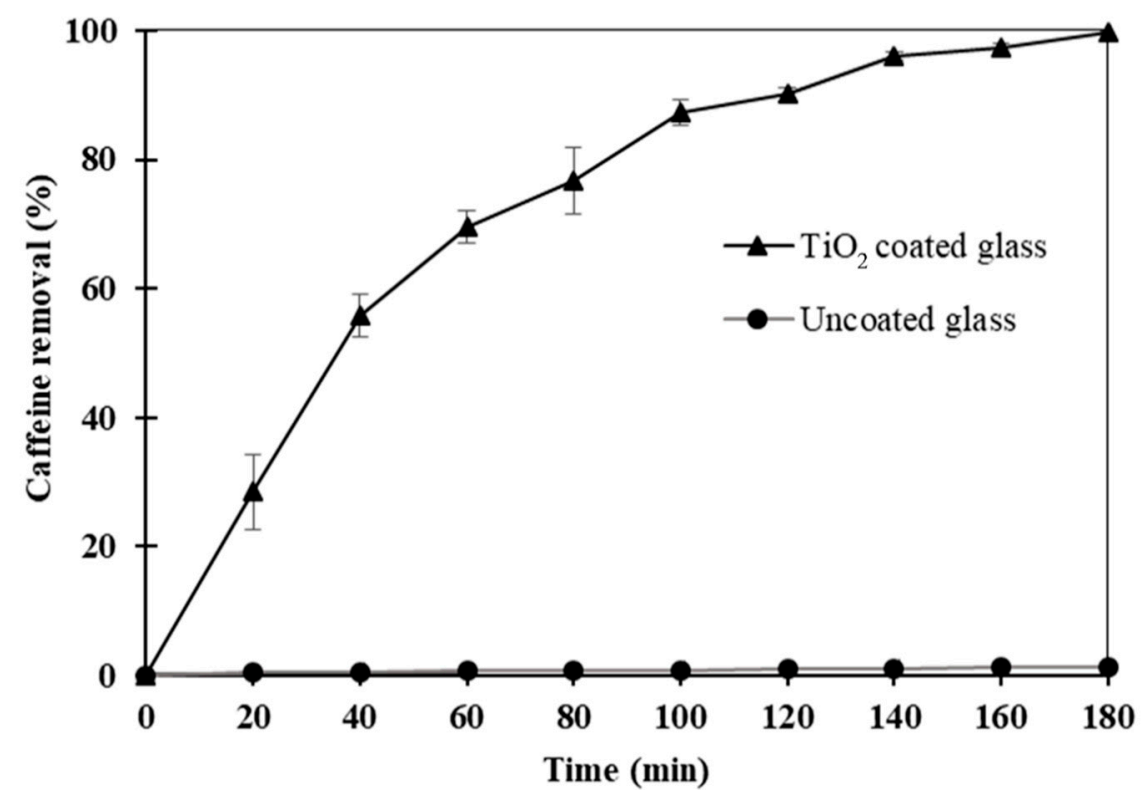

Figure 3. Efficiencies of caffeine removal under UVC irradiation at each irradiation time.

During irradiation of UV light over the $\mathrm{TiO}_{2}$ photocatalyst, the electron-hole pairs can be generated. The photo-excited electrons are transferred from the valence band to the conduction band, leaving the positive holes in the valence band. Subsequently, the photo-excited electrons and holes can migrate from bulk to the surface of $\mathrm{TiO}_{2}$, reacting with the surface adsorbed molecules to produce hydroxyl radicals. These radicals can degrade the surface of adsorbed caffeine molecules to obtain more readily degradable intermediate species and final harmless products according to the equations reported by Nosaka et al. [43], Li et al. [44], Abdellah et al. [45], and Ge et al. [46].

For the degradation mechanisms of caffeine by the photocatalytic process, the double bond of $\mathrm{C} 4$ and $\mathrm{C} 8$ in the caffeine molecule $\left(\mathrm{C}_{8} \mathrm{H}_{10} \mathrm{~N}_{4} \mathrm{O}_{2} ; \mathrm{Mw}=194\right)$ was rapidly attacked by hydroxyl radicals. After that, dimethylparabanic acid $\left(\mathrm{C}_{5} \mathrm{H}_{6} \mathrm{~N}_{2} \mathrm{O}_{3} ; \mathrm{Mw}=142\right)$ was formed as the first intermediate species and subsequently react with hydroxyl radicals to form di (N-hydroxymethyl) parabanic acid $\left(\mathrm{C}_{5} \mathrm{H}_{6} \mathrm{~N}_{2} \mathrm{O}_{5}, \mathrm{Mw}=174\right)$ as the second intermediate species. This second intermediate species could be gradually mineralized to $\mathrm{CO}_{2}, \mathrm{NH}_{3}$, and $\mathrm{NH}_{2} \mathrm{Me}$ [9].

\subsubsection{Effects of Initial Concentration}

The effects of initial concentration were studied using five different caffeine concentrations, which were 1, 5, 10, 20, and $40 \mathrm{mg} / \mathrm{L}$. The relationship between initial caffeine concentrations and photocatalytic removal efficiencies are revealed in Figure 4. At the same irradiation time, it was found that the removal efficiency of caffeine decreased with increasing initial caffeine concentration. The removal efficiencies achieved higher than 99\% after 40, 100, 140, 180, and $180 \mathrm{~min}$ of UVC irradiation for the initial caffeine concentrations of $1,5,10,20$, and $40 \mathrm{mg} / \mathrm{L}$, respectively. It can be concluded that the higher caffeine concentrations required more irradiation time than the lower caffeine concentrations for degradation. Luna et al. [13] also reported that the lower caffeine concentrations could be completely removed in shorter sunlight radiation time compared with the higher caffeine concentration. This phenomenon can be explained that some caffeine molecules in the concentrated solutions cannot contact the surface of $\mathrm{TiO}_{2}$ film to initiate the photocatalytic reaction [47]. 


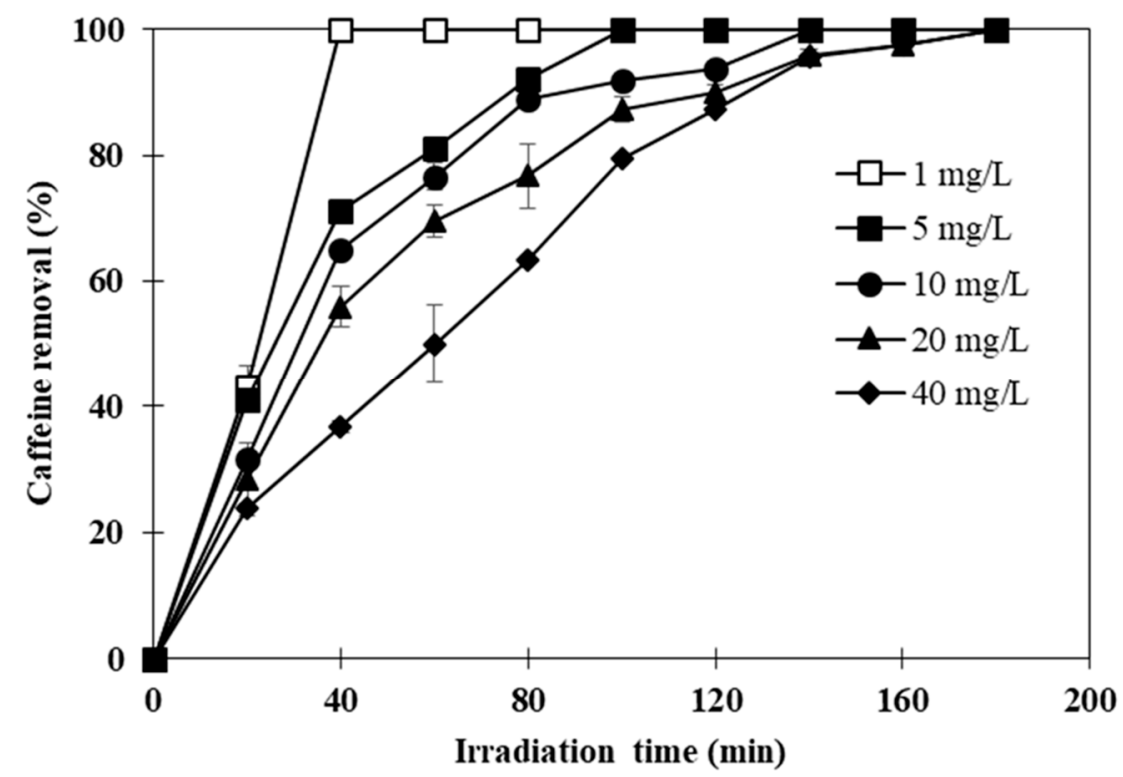

Figure 4. Efficiencies of caffeine removal under UVC irradiation at various initial concentrations of caffeine.

The kinetic plots of $\ln \left(\mathrm{C}_{0} / \mathrm{C}\right)$ versus irradiation time at various initial caffeine concentrations are revealed in Figure 5. It can be seen that photocatalytic degradation of caffeine at irradiation times of 0-80 min followed the pseudo-first-order kinetic model (Equation (1)). The apparent initial rate constant $\left(\mathrm{k} ; \mathrm{min}^{-1}\right)$ can be determined by the integration form of pseudo-first-order kinetic model (Equation (2)), where $\mathrm{C}_{0}$ is the initial caffeine concentration $(\mathrm{mg} / \mathrm{L}), \mathrm{t}$ is irradiation time (min), and $\mathrm{C}$ is the remained concentration of caffeine at a different irradiation time $(\mathrm{mg} / \mathrm{L})$.

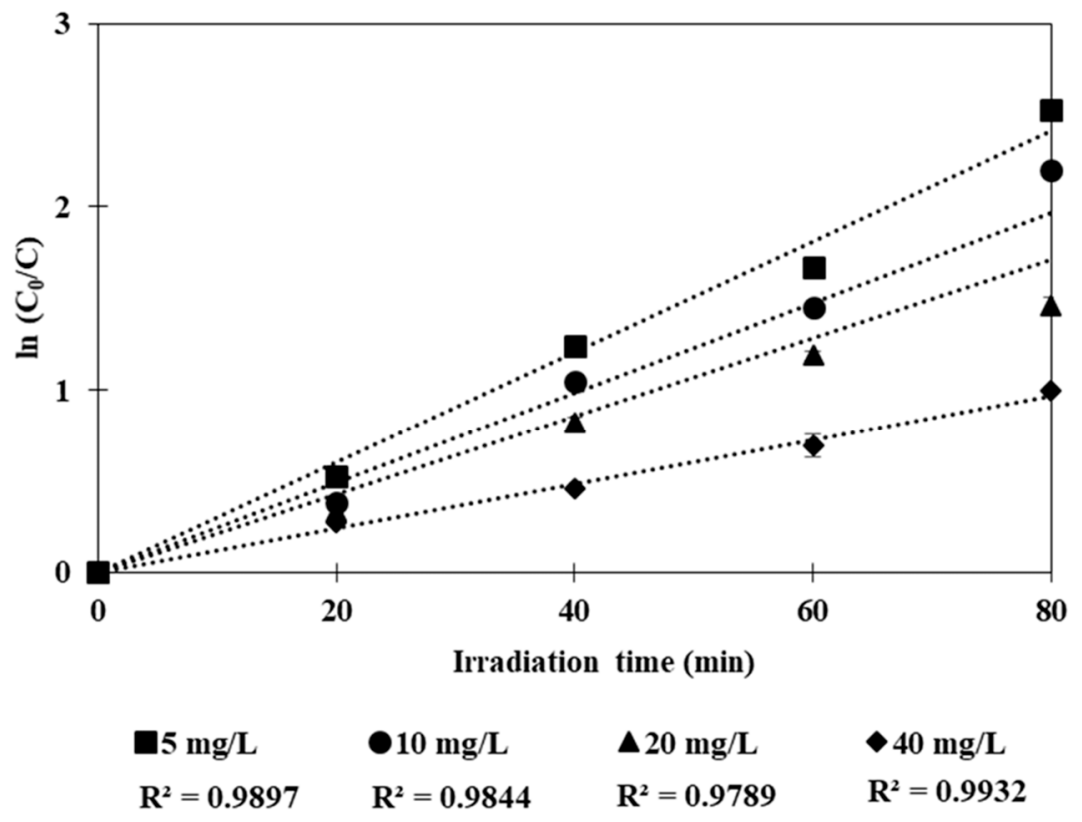

Figure 5. Pseudo-first-order kinetic plots for photocatalytic degradation of caffeine under UVC irradiation.

$$
\mathrm{r}=\mathrm{dC} / \mathrm{dt}=-\mathrm{kC}
$$




$$
\ln \left(\mathrm{C}_{0} / \mathrm{C}\right)=\mathrm{kt}
$$

The relationship between initial caffeine concentration and the apparent initial rate constant is shown in Figure 6. The apparent initial rate constant $(\mathrm{k})$ at initial caffeine concentration of 5, 10, 20, and $40 \mathrm{mg} / \mathrm{L}$ were $0.0302,0.0246,0.0214,0.0121 \mathrm{~min}^{-1}$, respectively. It could be noted that the apparent initial rate constant $(\mathrm{k})$ decreased with increasing initial caffeine concentration. These results are in agreement with other studies, which reported the photocatalytic degradation of caffeine using $\mathrm{TiO}_{2}$ powder. The degradation rate of caffeine followed the pseudo-first-order kinetics model. The initial apparent rate constant $(\mathrm{k})$ of caffeine degradation decreased with the increasing initial caffeine concentration $[5,13]$.

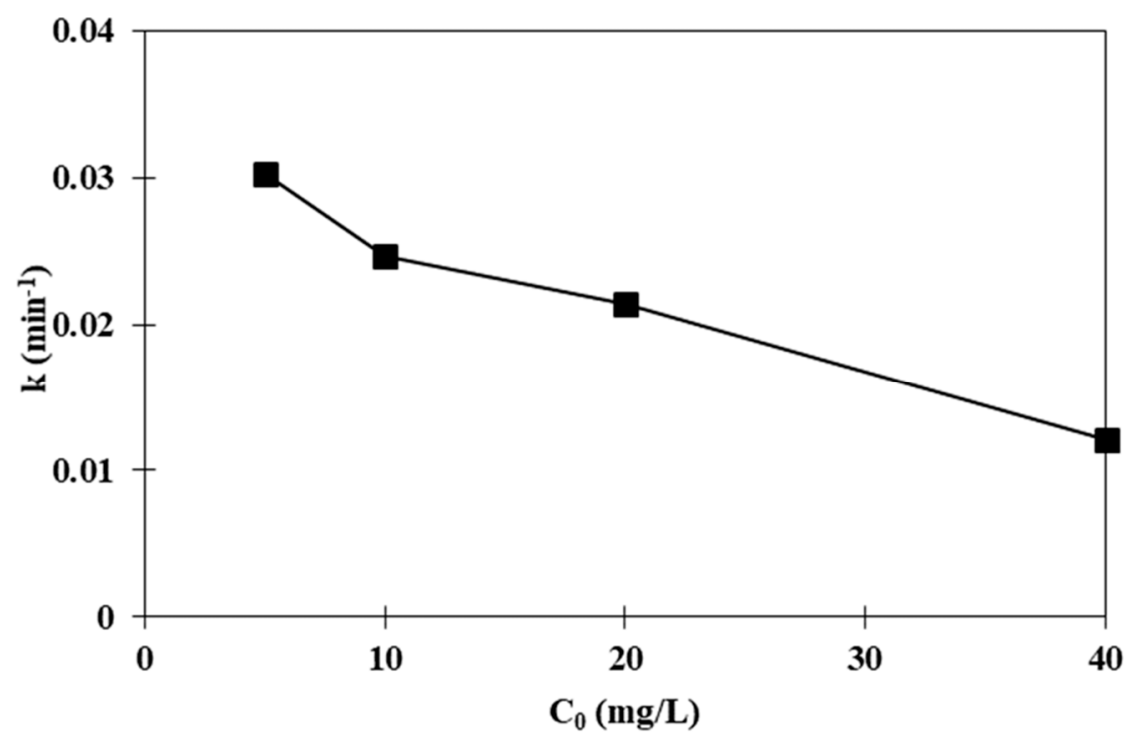

Figure 6. Effects of initial caffeine concentration on the initial pseudo-first-order rate constant of caffeine degradation under UVC irradiation.

\subsubsection{Reusability of Photocatalyst}

Reusability of the photocatalyst was investigated by repeating the use of $\mathrm{TiO}_{2}$-coated glasses for photocatalytic degradation of caffeine in fifteen consecutive cycles. After the photocatalytic experiment completed in each cycle, the $\mathrm{TiO}_{2}$-coated glasses were easily separated from the treated wastewater. Afterward, the $\mathrm{TiO}_{2}$-coated glasses and new caffeine solution was replaced in the container for the next cycle test. The treated wastewater was taken to investigate the adhesion of $\mathrm{TiO}_{2}$ film on the glass surface by microcentrifuge at 12,000 rpm for $3 \mathrm{~min}$. The water at the bottom of the microcentrifuge tubes was dropped on an SEM specimen stub. The water then evaporated. The stub was investigated by SEM. It was observed that no $\mathrm{TiO}_{2}$ powder settled at the bottom of the microcentrifuge tubes. This result indicated that the adhesion of $\mathrm{TiO}_{2}$ film on the glass surface was excellent. As can be seen in Figure 7, the removal efficiency of caffeine in each cycle maintained a high level $(\sim 100 \%)$ during fifteen consecutive cycles under UVC irradiation. This result indicated that the immobilization of $\mathrm{TiO}_{2}$ as a thin film on glass could solve the problem in the post-separation of $\mathrm{TiO}_{2}$ from treated wastewater, and they are reusable. 

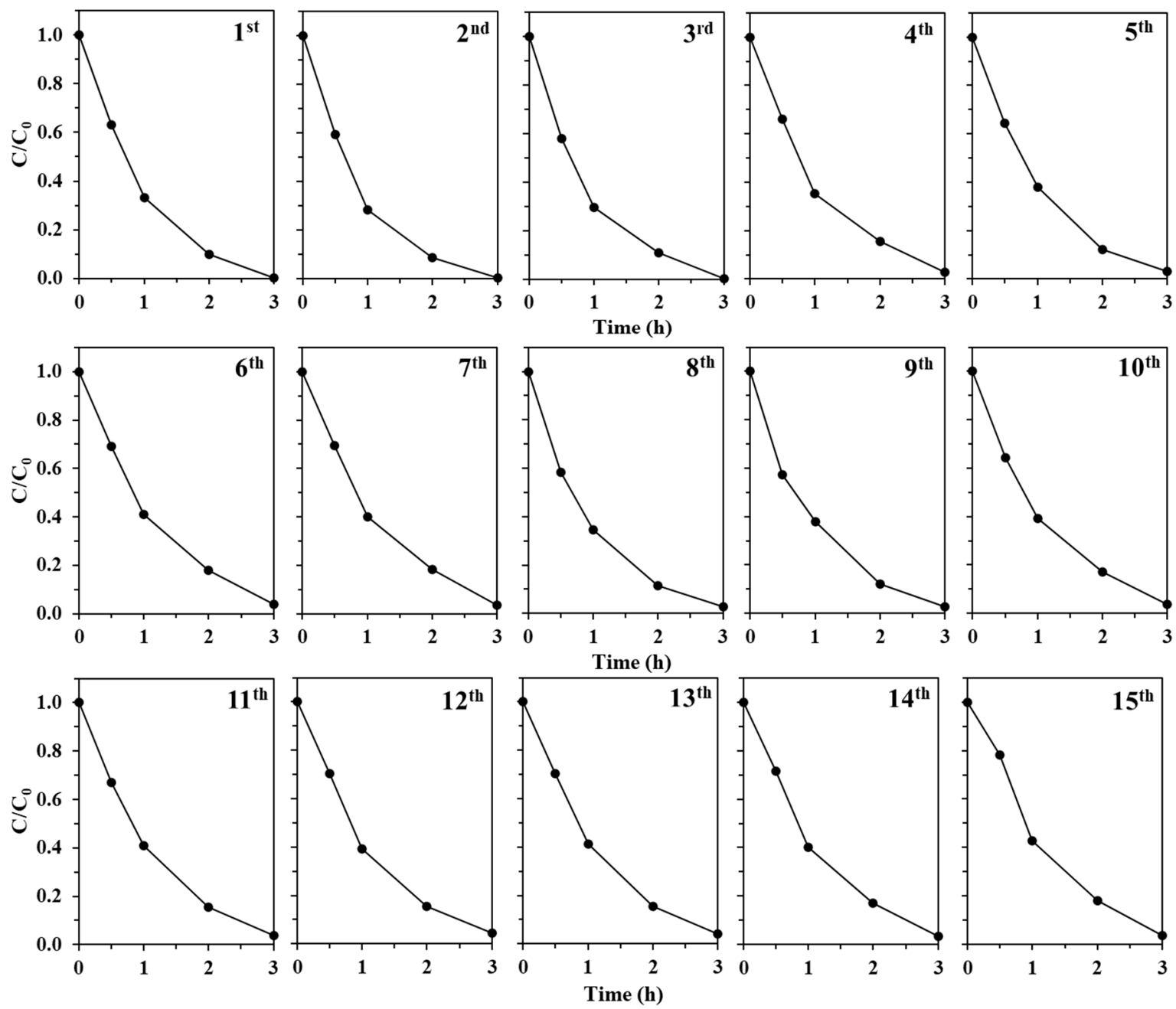

Figure 7. Reusability of $\mathrm{TiO}_{2}$ thin film immobilized on a glass substrate under UVC irradiation.

\section{Discussion}

$\mathrm{TiO}_{2}$ solution synthesized via the ultrasonic-assisted sol-gel method with polyvinylpyrrolidone showed a unique morphology and attached well to a circular glass sheet after coating. The thickness of the $\mathrm{TiO}_{2}$ film was properly controlled by tape strip in the doctor blade techniques. $\mathrm{TiO}_{2}$-coated glass exhibited high performance $(\sim 100 \%$, within $3 \mathrm{~h})$ and maintained a high performance after fifteen consecutive cycles in photocatalytic degradation of caffeine under UVC irradiation. Moreover, they were easy to handle and separate from the treated wastewater. In consideration of caffeine removal in the previous works (Table 1), it was found that the caffeine removal by the $\mathrm{TiO}_{2}$ powder system was almost complete within 3-8 h under solar light for the commercial $\mathrm{TiO}_{2}[5,13]$. For sol-gel synthesized $\mathrm{TiO}_{2}$ powder, the removal was $80 \%$ within $6 \mathrm{~h}$ under ultraviolet $\mathrm{A}$ (UVA) irradiation [48]. Whereas, the maximum efficiencies of caffeine removal were in the range of $50-65 \%$ within $4 \mathrm{~h}$ for the works that used $\mathrm{TiO}_{2}$ film [11] and $\mathrm{TiO}_{2}$ nanotube [11] as photocatalysts under UVA irradiation. Although the previous works showed that the complete removal could be achieved by using $\mathrm{TiO}_{2}$ powder in the degradation of caffeine, it is still inconvenient to apply on the full scale. This is because the $\mathrm{TiO}_{2}$ powder needs to be separated from the effluent by the microfiltration unit before discharging into the natural water bodies. As described above, it can be attributed that the coating procedure and the experimental set up under UVC irradiation in this study are proven to be one of the effective techniques for the treatment of caffeine in water, which can overcome the limitation of post-separation in the $\mathrm{TiO}_{2}$ powder system. The photocatalytic reactor under UVC irradiation in this study can be scaled up for the treatment of caffeine contaminated wastewater (e.g., wastewater from coffee processing, 
coffee shops) in a closed system until achieved complete removal. Afterward, the treated water can be discharged into the aquatic environment.

Table 1. Photocatalytic degradation of caffeine in the previously available studies and this study.

\begin{tabular}{|c|c|c|c|c|c|}
\hline Photocatalyst & $\begin{array}{c}\text { The Initial } \\
\text { Concentration } \\
\text { of Caffeine } \\
(\mathrm{mg} / \mathrm{L})\end{array}$ & Light Source & $\begin{array}{l}\text { Irradiation } \\
\text { Time } \\
\text { (h) }\end{array}$ & $\begin{array}{l}\text { Removal } \\
\text { Efficiency }\end{array}$ & Reference \\
\hline $\begin{array}{c}\text { Commercial } \mathrm{TiO}_{2} \\
\text { Evonik-Degussa } \\
\text { P25 (powder) }\end{array}$ & 20 & Natural Sunlight & 3 & $\sim 100 \%$ & [13] \\
\hline $\begin{array}{c}\text { Commercial } \mathrm{TiO}_{2} \\
\text { Sigma-Aldrich } \\
\text { (powder) }\end{array}$ & 30 & Solar simulator & 8 & $\sim 100 \%$ & [5] \\
\hline $\begin{array}{l}\mathrm{TiO}_{2} \text { synthesized } \\
\text { by sol-gel } \\
\text { method (powder) }\end{array}$ & 25 & UVA-LED strip & 6 & $80 \%$ & [48] \\
\hline $\begin{array}{c}\text { Commercial } \mathrm{TiO}_{2} \\
\text { Evonik-Degussa } \\
\text { P25 coated on } \\
\text { microscopy glass }\end{array}$ & 15 & UVA lamp & 4 & $\sim 65 \%$ & [11] \\
\hline $\begin{array}{l}\mathrm{TiO}_{2} \text { nanotube } \\
\text { synthesized by } \\
\text { electrochemical } \\
\text { anodization }\end{array}$ & 15 & UVA lamp & 4 & $\sim 50 \%$ & [11] \\
\hline $\begin{array}{c}\mathrm{TiO}_{2} \text { film } \\
\text { synthesized by } \\
\text { sol-gel method } \\
\text { coated on the } \\
\text { circular glass sheet }\end{array}$ & 20 & UVC lamp & 3 & $\sim 100 \%$ & This study \\
\hline
\end{tabular}

\section{Materials and Methods}

\subsection{Materials}

Titanium (IV) butoxide (TBOT, purity $97 \%)$ and caffeine powder $\left(\mathrm{C}_{8} \mathrm{H}_{10} \mathrm{~N}_{4} \mathrm{O}_{2}\right.$, purity $\left.99 \%\right)$ were purchased from Sigma-Aldrich (Shanghai, China). Polyvinylpyrrolidone (PVP, Mw =1,300,000) was purchased from Sigma-Aldrich (St. Louis, MO, USA). Methanol and 2-propanol were products of RCI Labscan (Bangkok, Thailand). Acetylacetone (ACA) was a product of Carlo Erba Reagents (Val de Reuil, France). All of the chemicals used were analytical grade. The circular transparent glass sheets (soda-lime glass, diameter $=8 \mathrm{~cm}$, thickness $=2 \mathrm{~mm}$, Samut Prakan, Thailand) were used as the supports of the $\mathrm{TiO}_{2}$ film.

\subsection{Preparation of $\mathrm{TiO}_{2}$ Immobilized Glass Sheets}

Circular transparent glass sheets were pretreated by immersion in 2-propanol for 30 min to remove impurities. They were then dried in an oven (Binder, Model FD115, Tuttlingen, Germany) at $105^{\circ} \mathrm{C}$ for $1 \mathrm{~h}$. The $\mathrm{TiO}_{2}$ gel solution was prepared by the ultrasonic-assisted sol-gel method. PVP (0.8 g) was dissolved in methanol $(20 \mathrm{~mL})$ and stirred for $30 \mathrm{~min}$. TBOT $(4 \mathrm{~g})$ and ACA $(1.175 \mathrm{~g})$ were subsequently added into the mixture. The mixture was stirred again for $30 \mathrm{~min}$ and checked in an ultrasonic clean bath (Crest Ultrasonics, Model 690HTAE, New York, NY, USA) at $50 \mathrm{kHz}$ at room temperature for $30 \mathrm{~min}$. After that, the $\mathrm{TiO}_{2}$ gel solution $(1 \mathrm{~mL})$ was dropped on the surface of a glass sheet and immobilized by the doctor blade technique (using a glass rod as the blade with plastic films as the frames). The immobilized glasses were dried in an oven at $105^{\circ} \mathrm{C}$ for $1 \mathrm{~h}$ and were then calcined in an 
electric muffle furnace (Carbolite, Model CWF 11/13, Sheffield, UK) at $500{ }^{\circ} \mathrm{C}$ for $2 \mathrm{~h}$. The obtained $\mathrm{TiO}_{2}$ film immobilized glass sheet is shown in Figure 8.

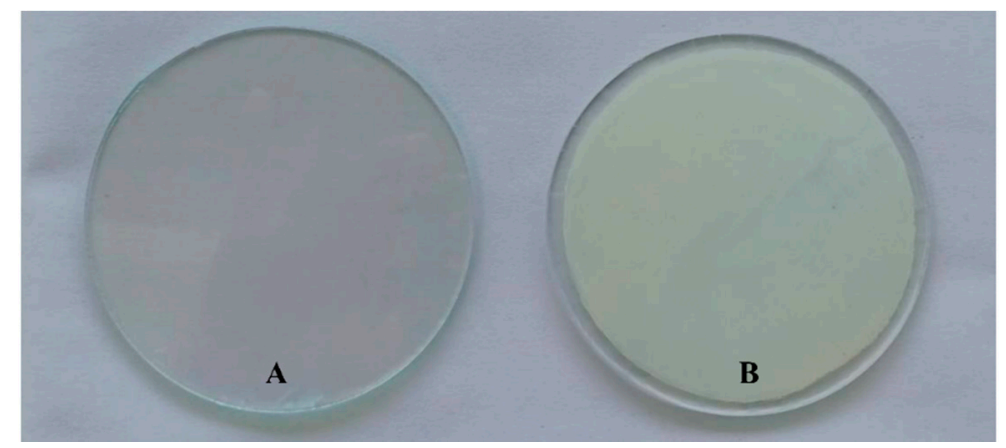

Figure 8. Circular glass sheets (A) before and (B) after immobilization of $\mathrm{TiO}_{2}$ film.

\subsection{Characterizations}

The $\mathrm{TiO}_{2}$ film immobilized glass sheets were cut into $1 \times 1 \mathrm{~cm}^{2}$ and coated by gold for determination of the surface and the cross-section morphology by a JEOL JSM-6610LV scanning electron microscope (SEM, Peabody, Massachusetts, MA, USA) operated at $15 \mathrm{kV}$ with the magnifications of $5000 \times$ and $10,000 \times$. The sheets were cut into $2 \times 2 \mathrm{~cm}^{2}$ to characterize the crystalline structure of $\mathrm{TiO}_{2}$ by a AXS Bruker D8 DISCOVER X-ray diffractometer (XRD, Coventry, UK) with Cu-K $\alpha$ radiation at the wavelength of $0.15406 \mathrm{~nm}$. The Scherrer's formula (Equation (3)) was used to determine the crystallite size of $\mathrm{TiO}_{2}(\tau)$ from the broadening of the (101) reflection of anatase [49].

$$
\mathrm{T}=\mathrm{K} \lambda / \beta \cos \theta
$$

where $\mathrm{K}$ is the form of factor (0.9), $\beta$ is the width of the peak at half the maximum intensity after subtraction of the instrumental noise, and $\theta$ is the diffraction angle.

\subsection{Photocatalytic Reactor}

The photocatalytic reactor in this experiment is shown in Figure 9. The setup is in a rectangular plywood chamber with $50 \times 50 \times 70 \mathrm{~cm}^{3}$ in dimensions. The irradiation was performed using four ultraviolet C (UVC) $16.7 \mathrm{~W}$ lamps (Philips, TUV F17T8, wavelength $=253.7 \mathrm{~nm}$ ). The UVC lamps were installed on the top of the chamber. Note that UVC radiation was chosen as a light source because of its high energy, which can induce high performance in the photocatalytic process within a short irradiation time. The photocatalytic reactor under UVC irradiation in this study can be scaled up for the treatment of actual caffeine wastewater in a closed system until achieved complete removal. Afterward, the treated water will be discharged into the aquatic environment. Human and other life forms in the aquatic environment will not expose to the UVC ray from this process. The containers for caffeine solutions (inside diameter $=9 \mathrm{~cm}$, height $=1.5 \mathrm{~cm}$ ) were placed in a mechanical shaker (60 rpm) at a distance of $25 \mathrm{~cm}$ from the irradiation source. The immobilized glass sheets were placed at the bottoms of the glass containers. 


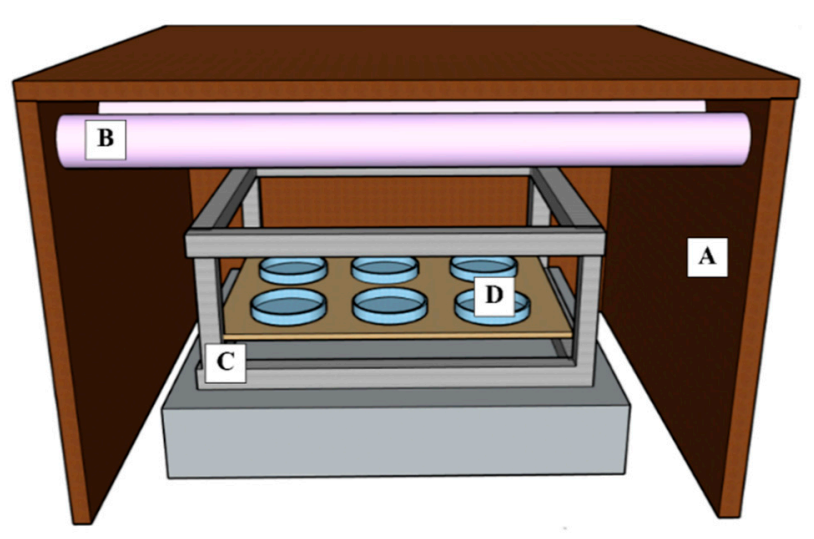

Figure 9. Set up of the photocatalytic reactor: (A) a rectangular plywood chamber, (B) UVC lamps, (C) a mechanical shaker, and (D) containers for samples.

\subsection{Photocatalytic Experiment}

The caffeine solution was prepared in deionized water. The solution $(25 \mathrm{~mL})$ was added into the prepared container. An immobilized glass sheet was soaked in the solution for $1 \mathrm{~h}$ in the dark to attain equilibrium adsorption. Subsequently, the UVC lamps were turned on and samples were collected every time intervals of $20 \mathrm{~min}$ until $180 \mathrm{~min}$. For the initial concentration experiment, caffeine solutions were prepared at concentrations of $1,5,10,20$, and $40 \mathrm{mg} / \mathrm{L}$. In the case of a reusability experiment, the immobilized glass sheet was tested for fifteen consecutive cycles. The treated caffeine solution was changed before the next cycle.

\subsection{Analysis of Caffeine Concentration}

The collected sample was filtered by a nylon syringe filter (diameter of $0.22 \mu \mathrm{m}$ ). After that, the filtered solution was analyzed by high performance liquid chromatography (HPLC) using an Alliance Waters e2695 instrument (Milford, Massachusetts, MA, USA) equipped with a photodiode array detector (Waters 2998) and a Vertisep AQS C18 HPLC column $(4.6 \mathrm{~mm} \times 150 \mathrm{~mm}, 5 \mu \mathrm{m})$. A solvent was pumped at a fixed flow rate of $1 \mathrm{~mL} / \mathrm{min}$. The mobile phase consisted of ultra-pure water $(50 \%)$ and methanol $(50 \%)$. Each sample $(10 \mu \mathrm{L})$ was automatically injected for analysis of caffeine concentration at the wavelength of $254 \mathrm{~nm}$. The peak area of caffeine was displayed on the chromatogram after 3 min of the sample injection.

\section{Conclusions}

$\mathrm{TiO}_{2}$ synthesized through the ultrasonic-assisted sol-gel method was successfully immobilized as a film on the circular glass sheets. Polyvinylpyrrolidone was used to mix with the $\mathrm{TiO}_{2}$ precursor solution to enhance film adhesion on the glass surface. The direct photolysis under UVC irradiation was proven to be ineffective for caffeine removal. On the other hand, the efficiency of caffeine removal by the photocatalytic oxidation process strongly depended on the time of UVC irradiation and the initial concentration of caffeine. The completed degradation of caffeine in aqueous solutions could be achieved by increasing irradiation time up to $180 \mathrm{~min}$. The degradation rate of caffeine followed the pseudo-first-order kinetic model and tended to increase with decreasing initial caffeine concentration. Furthermore, $\mathrm{TiO}_{2}$-coated glass sheets could be reused as a photocatalyst for water treatment without a significant decrease in its activity after fifteen consecutive cycles.

Author Contributions: Conceptualization-P.K. and S.C.; Analysis and discussion of the characterization results-R.M., P.K., and S.C.; Supervision-P.K.; Experiments and writing of the original manuscript-R.M.; Manuscript corrections-P.K., P.P., and S.C. All authors have read and agreed to the published version of the manuscript. 
Funding: This research was funded by The Thailand Science Research and Innovation (TSRI) and the Office of The Higher Education Commission (grant No. MRG6280178), Research Strengthening Project of the Faculty of Engineering, King Mongkut's University of Technology Thonburi, and the 55th Anniversary Commemorative Fund of King Mongkut's University of Technology Thonburi (KMUTT).

Acknowledgments: The author (Muangmora, R.) would like to acknowledge the academic supports from Petchra Pra Jom Klao Ph.D. Research Scholarship, King Mongkut's University of Technology Thonburi. Technical supports from the Department of Environmental Engineering and Department of Tool and Materials Engineering, Faculty of Engineering, KMUTT, are also gratefully acknowledged. The authors also thank Panipa Lohasuwan, Pattaraporn Danupatham, and Wachirapat Arunlakdamrong for their experimental helps.

Conflicts of Interest: The authors declare no conflict of interest.

\section{References}

1. Cardenas, M.A.R.; Ali, I.; Lai, F.Y.; Dawes, L.; Thier, R.; Rajapakse, J. Removal of micropollutants through a biological wastewater treatment plant in a subtropical climate, Queensland-Australia. J. Environ. Health Sci. Eng. 2016, 14, 14-23. [CrossRef]

2. Turner, R.D.; Warne, M.S.J.; Dawes, L.A.; Thompson, K.; Will, G.D. Greywater irrigation as a source of organic micro-pollutants to shallow groundwater and nearby surface water. Sci. Total Environ. 2019, 669, 570-578. [CrossRef]

3. Indermuhle, C.; De Vidales, M.J.M.; Sáez, C.; Robles, J.; Cañizares, P.; García-Reyes, J.F.; Molina-Díaz, A.; Comninellis, C.; Rodrigo, M.A. Degradation of caffeine by conductive diamond electrochemical oxidation. Chemosphere 2013, 93, 1720-1725. [CrossRef]

4. Marques, R.R.; Sampaio, M.J.; Carrapiço, P.M.; Silva, C.G.; Morales-Torres, S.; Dražić, G.; Faria, J.L.; Silva, A.M. Photocatalytic degradation of caffeine: Developing solutions for emerging pollutants. Catal. Today 2013, 209, 108-115. [CrossRef]

5. Ghosh, M.; Manoli, K.; Shen, X.; Wang, J.H.; Ray, A.K. Solar photocatalytic degradation of caffeine with titanium dioxide and zinc oxide nanoparticles. J. Photochem. Photobiol. A 2019, 377, 1-7. [CrossRef]

6. Arnaud, M. The Pharmacology of Caffeine. In Progress in Drug Research/Fortschritte Der Arzneimittelforschung/ Progrès Des Recherches Pharmaceutiques; Birkhäuser: Basel, Switzerland, 1987; pp. 273-313.

7. Edwards, Q.A.; Kulikov, S.M.; Garner-O'Neale, L.D. Caffeine in surface and wastewaters in Barbados, West Indies. SpringerPlus 2015, 4, 1-12. [CrossRef]

8. Elhalil, A.; Elmoubarki, R.; Farnane, M.; Machrouhi, A.; Sadiq, M.; Mahjoubi, F.; Qourzal, S.; Barka, N. Photocatalytic degradation of caffeine as a model pharmaceutical pollutant on $\mathrm{Mg}$ doped $\mathrm{ZnO}-\mathrm{Al}_{2} \mathrm{O}_{3}$ heterostructure. Environ. Nanotechnol. Monit. Manag. 2018, 10, 63-72. [CrossRef]

9. Chuang, L.C.; Luo, C.H.; Huang, S.W.; Wu, Y.C.; Huang, Y.C. Photocatalytic Degradation Mechanism and

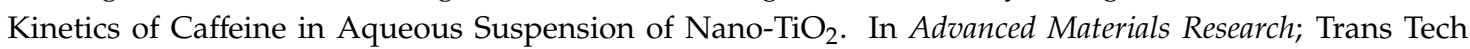
Publications Ltd.: Stafa-Zurich, Switzerland, 2011; Volume 214, pp. 97-102.

10. Zarrelli, A.; DellaGreca, M.; Iesce, M.R.; Lavorgna, M.; Temussi, F.; Schiavone, L.; Criscuolo, E.; Parrella, A.; Previtera, L.; Isidori, M. Ecotoxicological evaluation of caffeine and its derivatives from a simulated chlorination step. Sci. Total Environ. 2014, 470, 453-458. [CrossRef]

11. Arfanis, M.K.; Adamou, P.; Moustakas, N.G.; Triantis, T.M.; Kontos, A.G.; Falaras, P. Photocatalytic degradation of salicylic acid and caffeine emerging contaminants using titania nanotubes. Chem. Eng. J. 2017, 310, 525-536. [CrossRef]

12. Buerge, I.J.; Poiger, T.; Müller, M.D.; Buser, H.R. Caffeine, an anthropogenic marker for wastewater contamination of surface waters. Environ. Sci. Technol. 2003, 37, 691-700. [CrossRef]

13. Luna, R.; Solis, C.; Ortiz, N.; Galicia, A.; Sandoval, F.; Zermeño, B.; Moctezuma, E. Photocatalytic Degradation of Caffeine in a Solar Reactor System. Int. J. Chem. React. Eng. 2018, 16, 1-10. [CrossRef]

14. Moore, M.; Greenway, S.; Farris, J.; Guerra, B. Assessing caffeine as an emerging environmental concern using conventional approaches. Arch. Environ. Contam. Toxicol. 2008, 54, 31-35. [CrossRef]

15. Pires, A.; Almeida, Â.; Calisto, V.; Schneider, R.J.; Esteves, V.I.; Wrona, F.J.; Soares, A.M.; Figueira, E.; Freitas, R. Long-term exposure of polychaetes to caffeine: Biochemical alterations induced in Diopatra neapolitana and Arenicola marina. Environ. Pollut. 2016, 214, 456-463. [CrossRef] 
16. Fernandes, A.; Mello, F.; Thode Filho, S.; Carpes, R.; Honório, J.; Marques, M.; Felzenszwalb, I.; Ferraz, E. Impacts of discarded coffee waste on human and environmental health. Ecotoxicol. Environ. Saf. 2017, 141, 30-36. [CrossRef]

17. Rosal, R.; Rodríguez, A.; Perdigón-Melón, J.A.; Petre, A.; García-Calvo, E.; Gómez, M.J.; Agüera, A.; Fernández-Alba, A.R. Degradation of caffeine and identification of the transformation products generated by ozonation. Chemosphere 2009, 74, 825-831. [CrossRef]

18. Souza, F.S.; Féris, L.A. Degradation of caffeine by advanced oxidative processes: $\mathrm{O}_{3}$ and $\mathrm{O}_{3} / \mathrm{UV}$. Ozone Sci. Eng. 2015, 37, 379-384. [CrossRef]

19. Klamerth, N.; Malato, S.; Maldonado, M.; Aguera, A.; Fernández-Alba, A. Application of photo-Fenton as a tertiary treatment of emerging contaminants in municipal wastewater. Environ. Sci. Technol. 2010, 44, 1792-1798. [CrossRef]

20. Trovó, A.G.; Silva, T.F.; Gomes, O., Jr.; Machado, A.E.; Neto, W.B.; Muller, P.S., Jr.; Daniel, D. Degradation of caffeine by photo-Fenton process: Optimization of treatment conditions using experimental design. Chemosphere 2013, 90, 170-175.

21. Gould, J.; Richards, J. The kinetics and products of the chlorination of caffeine in aqueous solution. Water Res. 1984, 18, 1001-1009. [CrossRef]

22. Shu, Z.; Bolton, J.R.; Belosevic, M.; El Din, M.G. Photodegradation of emerging micropollutants using the medium-pressure $\mathrm{UV} / \mathrm{H}_{2} \mathrm{O}_{2}$ advanced oxidation process. Water Res. 2013, 47, 2881-2889. [CrossRef]

23. Muangmora, R.; Kemacheevakul, P.; Chuangchote, S. Titanium dioxide and its modified forms as photocatalysts for air treatment. Curr. Anal. Chem. 2020, 16, in press. [CrossRef]

24. Srisasiwimon, N.; Chuangchote, S.; Laosiripojana, N.; Sagawa, T. TiO 2 /lignin-based carbon composited photocatalysts for enhanced photocatalytic conversion of lignin to high value chemicals. ACS Sustain. Chem. Eng. 2018, 6, 13968-13976. [CrossRef]

25. Sudha, D.; Sivakumar, P. Review on the photocatalytic activity of various composite catalysts. Chem. Eng. Process 2015, 97, 112-133. [CrossRef]

26. Ahmad, R.; Ahmad, Z.; Khan, A.U.; Mastoi, N.R.; Aslam, M.; Kim, J. Photocatalytic systems as an advanced environmental remediation: Recent developments, limitations and new avenues for applications. J. Environ. Chem. Eng. 2016, 4, 4143-4164. [CrossRef]

27. Awfa, D.; Ateia, M.; Fujii, M.; Johnson, M.S.; Yoshimura, C. Photodegradation of pharmaceuticals and personal care products in water treatment using carbonaceous- $\mathrm{TiO}_{2}$ composites: A critical review of recent literature. Water Res. 2018, 142, 26-45.

28. Pathakoti, K.; Manubolu, M.; Hwang, H.M. Nanotechnology Applications for Environmental Industry. In Handbook of Nanomaterials for Industrial Applications; Hussain, C.M., Ed.; Elsevier: Amsterdam, The Netherlands, 2018; pp. 894-907.

29. Bouarioua, A.; Zerdaoui, M. Photocatalytic activities of $\mathrm{TiO}_{2}$ layers immobilized on glass substrates by dip-coating technique toward the decolorization of methyl orange as a model organic pollutant. J. Environ. Chem. Eng. 2017, 5, 1565-1574. [CrossRef]

30. Laamari, M.; Ben Youssef, A.; Bousselmi, L. Electrophoretic deposition of titanium dioxide films on copper in aqueous media. Water Sci. Technol. 2016, 74, 424-430. [CrossRef]

31. Sirirerkratana, K.; Kemacheevakul, P.; Chuangchote, S. Color removal from wastewater by photocatalytic process using titanium dioxide-coated glass, ceramic tile, and stainless steel sheets. J. Clean Prod. 2019, 215, 123-130. [CrossRef]

32. Hasan, A.; Waibhaw, G.; Tiwari, S.; Dharmalingam, K.; Shukla, I.; Pandey, L.M. Fabrication and characterization of chitosan, polyvinylpyrrolidone, and cellulose nanowhiskers nanocomposite films for wound healing drug delivery application. J. Biomed. Mater. Res. A 2017, 105, 2391-2404. [CrossRef]

33. Xie, H.; Liu, B.; Zhao, X. Facile process to greatly improve the photocatalytic activity of the $\mathrm{TiO}_{2}$ thin film on window glass for the photodegradation of acetone and benzene. Chem. Eng. J. 2016, 284, 1156-1164. [CrossRef]

34. Albano, G.; Evangelisti, C.; Aronica, L.A. Hydrogenolysis of Benzyl Protected Phenols and Aniline Promoted by Supported Palladium Nanoparticles. ChemistrySelect 2017, 2, 384-388. [CrossRef]

35. Albano, G.; Interlandi, S.; Evangelisti, C.; Aronica, L.A. Polyvinylpyridine-Supported Palladium Nanoparticles: A Valuable Catalyst for the Synthesis of Alkynyl Ketones via Acyl Sonogashira Reactions. Catal. Lett. 2020, 150, 652-659. [CrossRef] 
36. Chaudhuri, B.; Mondal, B.; Ray, S.; Sarkar, S. A novel biocompatible conducting polyvinyl alcohol (PVA)-polyvinylpyrrolidone (PVP)-hydroxyapatite (HAP) composite scaffolds for probable biological application. Coll. Surf. B Biointerfaces 2016, 143, 71-80. [CrossRef] [PubMed]

37. Zhang, L.; Feng, G. A one-step-assembled three-dimensional network of silver/polyvinylpyrro lidone (PVP) nanowires and its application in energy storage. Nanoscale 2020, 12, 10573-10583. [CrossRef] [PubMed]

38. Yao, J.; Takahashi, M.; Yoko, T. Controlled preparation of macroporous $\mathrm{TiO}_{2}$ films by photo polymerization-induced phase separation method and their photocatalytic performance. Thin Solid Films 2009, 517, 6479-6485. [CrossRef]

39. Jiang, H.; Dai, H.; Meng, X.; Zhang, L.; Deng, J.; Liu, Y.; Au, C.T. Hydrothermal fabrication and visible-light-driven photocatalytic properties of bismuth vanadate with multiple morphologies and/or porous structures for Methyl Orange degradation. J. Environ. Sci. 2012, 24, 449-457. [CrossRef]

40. Ohno, T.; Sarukawa, K.; Tokieda, K.; Matsumura, M. Morphology of a $\mathrm{TiO}_{2}$ photocatalyst (Degussa, P-25) consisting of anatase and rutile crystalline phases. J. Catal. 2001, 203, 82-86. [CrossRef]

41. Neppolian, B.; Wang, Q.; Jung, H.; Choi, H. Ultrasonic-assisted sol-gel method of preparation of $\mathrm{TiO}_{2}$ nano-particles: Characterization, properties and 4-chlorophenol removal application. Ultrason. Sonochem. 2007, 15, 649-658. [CrossRef]

42. Moghaddam, H.M.; Nasirian, S. Ultrasonic wave effects on the diameter of $\mathrm{TiO}_{2}$ nanoparticles. S. Afr. J. Sci. 2011, 107, 01-05.

43. Nosaka, Y.; Nakamura, M.; Hirakawa, T. Behavior of superoxide radicals formed on $\mathrm{TiO}_{2}$ powder photocatalysts studied by a chemiluminescent probe method. Phys. Chem. Chem. Phys. 2002, 4, 1088-1092. [CrossRef]

44. Li, M.; Yin, J.J.; Wamer, W.G.; Lo, Y.M. Mechanistic characterization of titanium dioxide nanoparticle-induced toxicity using electron spin resonance. J. Food Drug Anal. 2014, 22, 76-85. [CrossRef] [PubMed]

45. Abdellah, M.H.; Nosier, S.A.; El-Shazly, A.H.; Mubarak, A.A. Photocatalytic decolorization of methylene blue using $\mathrm{TiO}_{2} / \mathrm{UV}$ system enhanced by air sparging. Alex. Eng. J. 2018, 57, 3727-3735. [CrossRef]

46. Ge, J.; Zhang, Y.; Heo, Y.J.; Park, S.J. Advanced Design and Synthesis of Composite Photocatalysts for the Remediation of Wastewater: A Review. Catalysts 2019, 9, 122. [CrossRef]

47. Krivec, M.; Žagar, K.; Suhadolnik, L.; Čeh, M.; Dražić, G. Highly efficient $\mathrm{TiO}_{2}$-based microreactor for photocatalytic applications. ACS Appl. Mater. Interfaces 2013, 5, 9088-9094. [CrossRef] [PubMed]

48. Sacco, O.; Sannino, D.; Matarangolo, M.; Viano, V. Room Temperature Synthesis of V-Doped TiO 2 and Its Photocatalytic Activity in the Removal of Caffeine under UV Irradiation. Materials 2019, 12, 911. [CrossRef]

49. Simonsen, M.E.; Jensen, H.; Li, Z.; Søgaard, E.G. Surface properties and photocatalytic activity of nanocrystalline titania films. J. Photochem. Photobiol. A 2008, 200, 192-200. [CrossRef] 